\title{
Efficacy of Petiveria Alliacea (Linneaus) leaf and root bark powder in the control of filariasis vector Culex Quinquefasciatus
}

\author{
Michael Olarewaju Akintan ${ }^{1 *}\left(\mathbb{D}\right.$, Joseph Onaolapo Akinneye ${ }^{2}$ and Oluwatosin Betty llelakinwa ${ }^{1}$
}

\begin{abstract}
Background: Mosquitoes are vectors of parasitic diseases such as malaria, lymphatic filariasis, yellow fever, and dengue fever among others. They are well known as public enemies for their noise nuisance, biting annoyance, sleeplessness, allergic reactions, and diseases transmission during the biting and feeding activities. This then necessitate the search for insecticides of plant origin which are bio-degradable, non-toxic, and readily available for man use.

Result: This study, evaluated the fumigant efficacy of the powder of $P$. alliacea to control the adult stage of Culex mosquito. Powder of Petiveria alliacea were administered at different dose of $(1 \mathrm{~g}, 2 \mathrm{~g}, 3 \mathrm{~g}, 4 \mathrm{~g}$, and $5 \mathrm{~g})$, respectively. Result obtained shows the fumigant effect of the powder were effective with percentage mortality of $18.33-60.00 \%$ for the leaf powder and $23.30-71.60 \%$ for the root powder within $2 \mathrm{~h}$ post-treatment period $(P<0.05)$. The synergistic effect of the leaf and root powder was also investigated. The lethal dosage $\left(\mathrm{LD}_{50}\right)$ of the leaf, root, and synergistic effect of leaf and root bark powder required to kill $50 \%$ of the adult Culex quinquefasciatus was $3.76 \mathrm{~g}, 2.86 \mathrm{~g}$, and 2.63 $\mathrm{g}$, respectively. However, $25.06 \mathrm{~g}, 15.25 \mathrm{~g}$, and $12.94 \mathrm{~g}$ of the leaf, root, and leaf and root powder were required to kill 90\% (LD $\left.{ }_{90}\right)$ after a 2-h exposure period.

Conclusion: These finding suggested $P$. alliacea powder could be a good source of insecticide which may be used for the production of biopesticides. The present findings have important implications in the practical control of adult mosquito by using botanical insecticides. These plant powders are easy to prepare, inexpensive, and safe for use in mosquito control.
\end{abstract}

Keywords: Petiveria alliacea, Bio-pesticide, Culex quinquefasciatus, Filariasis, Fumigant

\section{Background}

Mosquitoes are implicated as 'Public Enemy No. 1' (World Health Organization, 1996). Over 4500 species of mosquitoes have been recorded to be distributed throughout the world in about 34 genera; most of which belongs to the Anophelinae and Culicidae family (Ghosh, Mukherjee, Dutta, Roy, \& Mondal, 2013). Malaria is transmitted by female Anopheles mosquito; Aedes aegypti and some other mosquito species are responsible

\footnotetext{
* Correspondence: mykheldre004@gmail.com

'Department of Biology (Environmental Biology and Public Health Unit), Federal University of Technology, PMB 704, Akure, Ondo-State, Nigeria Full list of author information is available at the end of the article
}

for the transmission of Dengue and Chikungunya while Culex mosquito specifically have been implicated in the transmission of Lymphatic Filariasis, Bancroftian encephalitis, and West Nile Virus (Yerpude, Jogdand, \& Jogdand, 2013) These diseases not only cause mortality or morbidity among humans but also cause social, cultural, environmental, and economic loss of the society (Ghosh et al., 2013). Culex pipiens and Culex quinquefasciatus are the two Culex species with the most important public health importance capable of transmitting bancroftian encephalitis caused by West Nile virus and Japanese encephalitis. However, there are several other species of Culex that are of public health importance.

\section{Springer Open}

(ㅇ The Author(s). 2021 Open Access This article is licensed under a Creative Commons Attribution 4.0 International License, which permits use, sharing, adaptation, distribution and reproduction in any medium or format, as long as you give appropriate credit to the original author(s) and the source, provide a link to the Creative Commons licence, and indicate if changes were made. The images or other third party material in this article are included in the article's Creative Commons licence, unless indicated otherwise in a credit line to the material. If material is not included in the article's Creative Commons licence and your intended use is not permitted by statutory regulation or exceeds the permitted use, you will need to obtain permission directly from the copyright holder. To view a copy of this licence, visit http://creativecommons.org/licenses/by/4.0/. 
The approach to combat this disease largely relied on interruption of the disease transmission cycle by either targeting the mosquito larvae through spraying of stagnant waters that serve as breeding sites or by killing the adult mosquitoes using insecticides. The vector borne control strategies in Nigeria include the effective combination of insecticide treated nets and indoor residual spraying which has been an adequate control measure. Mosquito resistance to the currently used insecticides, the emergence of multi drug resistant strains of parasites has escalated the malaria problem in the affected countries (Oduola, Obansa, Ashiegbu, Otubanjo, \& Awolola, 2010).

Vector control is a major component of the World Health Organisation (WHO) global mosquito-borne diseases intervention strategy, and it aimed primarily at the indoor residual spraying and the use of insecticidetreated nets. Recently, these control measures have limitations, which include insecticide resistance as well as encumbrance in achieving high scope (Luz, Pinheiro, Silva, Monteiro, \& Prediger, 2016). Organochlorines, Carbamates, Organophosphates, and Pyrethroids have been recorded by WHO to all have been resisted by Culex quinquefasciatus. In Nigeria, the susceptibility status of many mosquitoes in to Dichlorodiphenyltrichloroethane (DDT) and other classes of insecticides including organochlorine, organophosphate, carbamates, and recently pyrethroid in different zones has been well documented (Awolola et al., 2007). Thus, synthetic insecticides have caused several problems including the development of resistant insect strains, ecological imbalance, harm to mammals, and non-target arthropods. These setbacks of the hitherto developed insecticides have made researchers in these areas to effortlessly find and produce environmentally safe alternatives. As part of traditional healthcare, medicinal plants have been used in most parts of the world for thousands of years (Ajayi \& Ojelere, 2010). The use of these plants by man in the treatment of ailments and diseases is a common practice in the developing countries. However, botanical insecticides may serve as suitable alternatives to synthetic insecticides in the future, as they are relatively safe, bio-degradable, and readily available in many parts of the world. Researchers have resorted to plant extracts as potent sources of natural bio-insecticides (Bekele, Petros, Tekie, \& Asfaw, 2014). Although insecticides of plant origin have been broadly used in the control of agricultural pests, a very limited extent has been used against insect vectors of public health importance. Although various compounds of plant sources have been documented as insecticides and larvicides, there is still a vast scope for the discovery of more effective plant products particularly in the indigenous flora of lesser studied countries like Nigeria.
Petiveria alliacea L. belongs to the family Phytolaccaceae and is considered to be the most primitive family of the Caryophyllales (Cronquist, 2002). There are over 17 genera and 120 pan-tropical species in this group which are mostly found in North and South America (Barroso, 2004). Petiveria alliacea commonly known as guinea henweed (Tarzon plant) is known for its strong acrid and pungent smell, in the rural areas where these plants are found, it has been said that its pungent smell are very toxic to mosquitoes, and mosquitoes are less seen in the same areas where this plant are found. All parts of the $P$. alliacea plant are useful and to date several biologically active compounds have been secluded. Most eminent among these constituents are sulfur compounds (similar to allicin, found in garlic and onion), flavonoids, triterpenes, steroids, saponins, polyphenols, fredelinol, pinitol, and allantoin (De Andrade et al., 2012). Crude extracts of $P$. alliacea have been shown to exhibit diverse neuropharmacological benefits including cognitive enhancing activity, as well as antinociceptive, antidepressant, anxiolytic, and anti-seizure properties (Luz et al., 2016). Pentane extracts of the roots have revealed the presence of several volatile constituents such as benzaldehyde (48.3\%), dibenzyl-disulfide (23.3\%), dibenzyltrisulfide $(9.4 \%)$, and stilbene (8.1\%). Whereas, benzaldehyde (54.8\%), benzyl-thiol (20.3\%), and dibenzyldisulfide $(18.0 \%)$ have been detected in the inflorescences. Compounds isolated from extracts (water, methanol, ethanol) of the entire plant include dibenzltrisulfide, benzyldehyde, benzopyran astilbin, and coumarin which, based on in vitro studies, have inhibited the growth of leukemia cells and several other strains of cancerous tumor cells (Alegre \& Clavo, 2007). Dibenzyltrisulfide has also been reported to have a toxic effect on the adult sweet potato weevil (Cylas formicarius) and adult coffee borer beetle (Hypothenemus hampei) (Schmelzer \& Gurib-Fakim, 2008). Antifeedant activity of leaf extracts was recorded against the grasshopper Zonocerus variegatus, and an allelopathic effect on germinating seeds was also noticed. Dibenzyl-trisulfide was not active on Bacillus subtilis and had little inhibitory effect on Cladosporium cucumerinum (Schmelzer \& Gurib-Fakim, 2008). However, when dibenzyl trisulphide was transformed to methyl-benzyl-sulfonic anhydride it was found to be effective in preventing the growth of Bacillus subtilis, Pseudomonas fluorescens, and Cladosporium cucumerinum. In vitro studies of the growth of seeds of several crops revealed that methanol and dichloromethanol leaf extracts had an allelopathic effect (Schmelzer \& Gurib-Fakim, 2008). Seeds sown in the soil were not affected. Furthermore, Petiveria alliacea has been shown to accumulate nitrates and has caused nitrate poisoning in cattle (Schmelzer \& Gurib-Fakim, 2008). Therefore, these plants can be grown in the rural 
communities as well in the urban community to mitigate the incidence of mosquitoes in the environments. Scientifically, there is paucity of literature on these plants to control mosquitoes. This opened an insight of studying these plants as bio-pesticide against mosquito population. This present research focuses on the fumigant toxicity of Petiveria alliacea leaf and root bark powder on the mortality of adult Culex quinquefasciatus, these plants has been said to possess various medicinal properties including antibacterial, antifungal, and anticancer constituents. The effectiveness of this plant powder against mosquito can determine how important it might be in our environments.

\section{Methods}

\section{Materials used}

Common name: guinea henweed (Tarzon plant), fresh plant (Petiveria alliacea), dried leaves, and root bark of $P$. alliacea, pulveriser, clean tray, filter paper/seiver, mortar and pestle, polyethylene bags, Culex quinquefasciatus.

\section{Plant materials collection}

Plant materials were collected from Oke-Geu Village located in Ondo East Local Government Area of Ondo Town, Ondo State, Nigeria. The plants were obtained precisely, at coordinates: $7^{0} 2^{\prime} 4^{\prime \prime \prime} \mathrm{N} / 4^{0} 53^{\prime} 24^{\prime \prime}$ E and kept separately in polythene bags and brought to the laboratory to be air dried for 30 days in the Department of Biology, Federal University of Technology, Akure.

\section{Collection and Culture of Mosquito species}

The wild larvae of Culex quinquefasciatus were collected from three regions, namely, Oke-Aro, Igoba, and Obaile, Akure, Ondo-State, and identified in Biology Department, Federal University of Technology, Akure. The culture maintained was under laboratory conditions of $27 \pm$ $1{ }^{\circ} \mathrm{C}$ and $70 \pm 5 \%$ relative humidity. The larvae were fed on a diet of yeast/biscuit powder. Newly formed pupae were collected and transferred from the trays to a cup containing water and placed in screened cages $(60 \times 30$ $\times 45 \mathrm{~cm}$ ) where the adult emerged. The adults were continuously provided with $10 \%$ sucrose solution in a jar with a cotton wool. On day 4 post-emergence, the adult females were deprived of sugar for $12 \mathrm{~h}$ then provided with a shaved albino rat placed in resting cages overnight for blood feeding. Wet filter paper was placed on the corners for egg laying and the lifecycle was repeated.

\section{Plant powder}

The plant materials were washed and air dried, and kept in a polythene bag after which they were pulverized using a grinding machine (Model 2140J).

\section{Bioassay test}

The plant powder (leaf and root bark) were tested on the mosquitoes at different grams of $(1 \mathrm{~g}, 2 \mathrm{~g}, 3 \mathrm{~g}, 4 \mathrm{~g}$, and $5 \mathrm{~g}$ ) respectively. Plastic containers of dimension 15 $\mathrm{cm}$ depth by $12 \mathrm{~cm}$ diameter were used for the laboratory experiment. Twenty (20) Adult Culex quinquefasciatus (Regardless of the sex, Adult Culex quinquefasciatus were selected randomly) were introduced into the containers with different treatments and covered with lid. Each experiment was replicated thrice after which the adult mortality was determined and recorded after $30 \mathrm{~min}$ interval for $2 \mathrm{~h}$. The control experiment was also replicated thrice.

\section{Percentage mortality}

The percentage mortality was calculated by using the formula (1), and corrections for mortality when necessary were done using Abbott's (1925) formula (2)

$$
\%_{\text {MORTALITY }}=\frac{N_{\text {dead adult }}}{N_{\text {adult introduced }}} \times 100
$$

Where $\%_{m}$ is the percentage mortality

$N_{\mathrm{da}}$ is the number of dead adult.

$N_{\text {ai }}$ is the number of adult introduced.

Corrected percentage mortality

$$
P_{\mathrm{T}}=\frac{P_{\mathrm{O}}-P_{\mathrm{C}}}{100-P_{\mathrm{C}}} \times 100
$$

Where

- $P_{\mathrm{T}}=$ corrected mortality $(\%)$

- $P_{\mathrm{O}}=$ observed mortality (\%)

- $P_{\mathrm{C}}=$ control mortality $(\%)$

\section{Statistical analysis}

All data were subjected to one-way analysis of variance (ANOVA) to check for significance using Duncan's new multiple range test at $P<0.05$ and then the mortality of each bioassay will be subjected to Probit analysis to determine $50 \%$ lethal concentration $\left(\mathrm{LC}_{50}\right)$ and the $90 \%$ lethal concentration $\left(\mathrm{LC}_{90}\right)$ using SPSS (Statistical Package for Social Sciences) version 20.0.

\section{Fumigant effect of leaf and root bark powder of $P$. alliacea on mortality of adult Culex quinquefasciatus}

Different grams (1 g, $2 \mathrm{~g}, 3 \mathrm{~g}, 4 \mathrm{~g}$, and $5 \mathrm{~g}$ ) of leaf or root bark powder were weighed in muslin cloths sown into sack of $3 \mathrm{~cm} \times 2 \mathrm{~cm}$ dimension and suspended with the aid of a thread at a distance of $7 \mathrm{~cm}$ from the lid of the plastic containers of dimension $15 \mathrm{~cm}$ depth and $12 \mathrm{~cm}$ diameter. Twenty adult mosquitoes (about $48 \mathrm{~h}$ old) were introduced into the plastic containers. Each 
containing the suspended bags of plant powders. The experiment was replicated three times and adult mortality was recorded after $30 \mathrm{~min}, 1 \mathrm{~h}, 1 \mathrm{~h} 30 \mathrm{~min}$, and $2 \mathrm{~h}$. The control experiment (in which adult mosquitoes were introduced into the container without treatment exposure) was also set up and replicated thrice.

\section{Synergistic effect of leaf and root bark powder of $P$. alliacea on mortality of adult Culex quinquefasciatus} Equal dose of the leaf and root bark powder are weighed up to ( $1 \mathrm{~g}, 2 \mathrm{~g}, 3 \mathrm{~g}, 4 \mathrm{~g}$, and $5 \mathrm{~g}$ ), respectively. The powder are admixed together to ensure homogeneous mixture of the powders. The plant powder were weighed in muslin cloths sown into sack of $3 \mathrm{~cm} \times 2 \mathrm{~cm}$ dimension and suspended with the aid of a thread at a distance of 7 $\mathrm{cm}$ from the lid of the plastic containers of dimension $15 \mathrm{~cm}$ depth and $12 \mathrm{~cm}$ diameter. Twenty adult mosquitoes (about $48 \mathrm{~h}$ old) were introduced into the plastic containers. Each containing the suspended bags of plant powders. The experiment was replicated three times and adult mortality was recorded after $30 \mathrm{~min}, 1 \mathrm{~h}, 1 \mathrm{~h} 30$ min, and $2 \mathrm{~h}$. The control experiment was also set up and replicated thrice.

\section{Result}

Fumigant toxicity of leaf powder of $P$. alliacea on the mortality of adult Culex quinquefasciatus

The fumigant effect of leaf powder of $P$. alliacea on the mortality of Culex quinquefasciatus is presented in Table 1. At all grams of the plant powder $(1 \mathrm{~g}, 2 \mathrm{~g}, 3 \mathrm{~g}, 4 \mathrm{~g}$, and $5 \mathrm{~g})$, there was no adult mortality at $30 \mathrm{~min}$ post-treatment periods. At $1 \mathrm{~h}$ post-treatment period $1-3 \mathrm{~g}$ of the powder were able to cause $5.00-18.33 \%$ adult mortality, while $4-5$ $\mathrm{g}$ of the powder caused $26.67 \%$ adult mortality respectively and were not significantly $(P>0.05)$ different from each other. At $1 \mathrm{~h} 30 \mathrm{~min}$ post-treatment periods $(1-5 \mathrm{~g})$ of the powder concentration were able to cause $11.67-48.33 \%$ adult mortality and are significantly $(P<0.05)$ different from one another. However, at $2 \mathrm{~h}$ post-treatment periods,

Table 1 Fumigant toxicity of Leaf powder of Petiveria alliacea on the mortality of adult Culex quinquefasciatus

\begin{tabular}{lllll}
\hline $\begin{array}{l}\text { Weight } \\
(\mathbf{g})\end{array}$ & \multicolumn{4}{l}{ \%Mortality after } \\
\cline { 2 - 5 } & $\mathbf{3 0} \mathbf{~} \mathbf{m i n}$ & $\mathbf{1 ~ h}$ & $\mathbf{1} \mathbf{~ h ~} \mathbf{3 0} \mathbf{~}$ in & $\mathbf{2 ~ \mathbf { ~ }}$ \\
\hline 1 & $0.00 \pm 0.00^{\mathrm{a}}$ & $5.00 \pm 0.00^{\mathrm{b}}$ & $11.67 \pm 0.33^{\mathrm{b}}$ & $18.33 \pm 0.67^{\mathrm{b}}$ \\
2 & $0.00 \pm 0.00^{\mathrm{a}}$ & $8.33 \pm 0.33^{\mathrm{b}}$ & $23.33 \pm 0.33^{\mathrm{c}}$ & $35.00 \pm 0.00^{\mathrm{c}}$ \\
3 & $0.00 \pm 0.00^{\mathrm{a}}$ & $18.33 \pm 0.33^{\mathrm{c}}$ & $30.00 \pm 0.58^{\mathrm{d}}$ & $43.33 \pm 0.88^{\mathrm{d}}$ \\
4 & $0.00 \pm 0.00^{\mathrm{a}}$ & $26.67 \pm 0.00^{\mathrm{d}}$ & $40.00 \pm 0.00^{\mathrm{e}}$ & $48.33 \pm 0.33^{\mathrm{d}}$ \\
5 & $0.00 \pm 0.00^{\mathrm{a}}$ & $26.67 \pm 0.33^{\mathrm{d}}$ & $48.33 \pm 0.33^{\mathrm{f}}$ & $60.00 \pm 0.00^{\mathrm{e}}$ \\
Control & $0.00 \pm 0.00^{\mathrm{a}}$ & $0.00 \pm 0.00^{\mathrm{a}}$ & $0.00 \pm 0.00^{\mathrm{a}}$ & $0.00 \pm 0.00^{\mathrm{a}}$ \\
\hline
\end{tabular}

Each value is the mean \pm standard error of three replicates. Mean followed by the same alphabet are not significantly $(P>0.05)$ different from each other using Duncan's new multiple range test
$1-2 \mathrm{~g}$ of the leaf powder caused $18.33-35.00 \%$ adult mortality and were significantly $(P<0.05)$ different from each other, while at $3-4 \mathrm{~g}$ powder concentration $43.30-48.30 \%$ adult mortality was attained and were not significantly $(P>$ 0.05 ) different from one another.

Powder concentration of $5 \mathrm{~g}$ shows a mortality count of $60.00 \%$ which is significantly $(P<0.05)$ different from all other concentration as well as the control.

\section{Fumigant toxicity of root bark powder of $P$. alliacea on the mortality of adult Culex quinquefasciatus}

The fumigant effect of root bark powder of $P$. alliacea on the mortality of adult Culex quinquefasciatus is presented in Table 2. At $1 \mathrm{~g}, 2 \mathrm{~g}, 3 \mathrm{~g}$, and $4 \mathrm{~g}$ of the root powder, there was no mortality at $30 \mathrm{~min}$ posttreatment periods; however, at $5 \mathrm{~g}$ powder concentration, a $5.00 \%$ adult mortality count was recorded which was significantly $(P<0.05)$ different from others as well as the control. At $1 \mathrm{~h}$ post-treatment periods, $1-2 \mathrm{~g}$ powder concentration caused $5.00-11.67 \%$ adult mortality respectively and were significantly $(P<0.05)$ different from each other, while 3-4 g powder concentration caused $26.67 \%$ adult mortality which were not significantly $\left(P^{>} 0.05\right)$ different from each other. However, $5 \mathrm{~g}$ powder concentration caused $40.00 \%$ adult mortality and was significantly $(P<0.05)$ different from all others. At $1 \mathrm{~h} 30 \mathrm{~min}$ post-treatment periods, 15.00$25.00 \%$ adult mortality was recorded and were significantly $(P<0.05)$ different from each other, while $3-4$ g powder concentration $38.33 \%$ adult mortality was recorded respectively and were not significantly $(P$ > 0.05 ) different from each other. However, at $5 \mathrm{~g}$ powder concentration, $58.33 \%$ adult mortality was recorded and was significantly $(P<0.05)$ different from all others. At $2 \mathrm{~h}$ post-treatment periods, $1-5 \mathrm{~g}$ powder concentration caused $23.33-71.67 \%$ adult mortality respectively and were significantly $(P<0.05)$ different from each other as well as the control.

Table 2 Fumigant toxicity of root bark powder of Petiveria alliacea on the mortality of adult Culex quinquefasciatus

\begin{tabular}{lllll}
\hline $\begin{array}{l}\text { Weight } \\
\text { (g) }\end{array}$ & \multicolumn{4}{l}{ \%Mortality after } \\
\cline { 2 - 5 } & $\mathbf{3 0} \mathbf{~} \mathbf{m i n}$ & $\mathbf{1} \mathbf{~ h}$ & $\mathbf{1 ~ h ~} \mathbf{3 0} \mathbf{~} \mathbf{~ i n}$ & $\mathbf{2 ~ h}$ \\
\hline 1 & $0.00 \pm 0.00^{\mathrm{a}}$ & $5.00 \pm 0.00^{\mathrm{b}}$ & $15.00 \pm 0.00^{\mathrm{b}}$ & $23.33 \pm 0.33^{\mathrm{b}}$ \\
2 & $0.00 \pm 0.00^{\mathrm{a}}$ & $11.67 \pm 0.33^{\mathrm{c}}$ & $25.00 \pm 0.00^{\mathrm{c}}$ & $36.67 \pm 0.33^{\mathrm{c}}$ \\
3 & $0.00 \pm 0.00^{\mathrm{a}}$ & $26.67 \pm 0.33^{\mathrm{d}}$ & $38.33 \pm 0.33^{\mathrm{d}}$ & $50.00 \pm 0.00^{\mathrm{d}}$ \\
4 & $0.00 \pm 0.00^{\mathrm{a}}$ & $26.67 \pm 0.33^{\mathrm{d}}$ & $38.33 \pm 0.33^{\mathrm{d}}$ & $56.67 \pm 0.67^{\mathrm{e}}$ \\
5 & $5.00 \pm 0.00^{\mathrm{b}}$ & $40.00 \pm 0.00^{\mathrm{e}}$ & $58.33 \pm 0.33^{\mathrm{e}}$ & $71.67 \pm 0.33^{\mathrm{f}}$ \\
Control & $0.00 \pm 0.00^{\mathrm{a}}$ & $0.00 \pm 0.00^{\mathrm{a}}$ & $0.00 \pm 0.00^{\mathrm{a}}$ & $0.00 \pm 0.00^{\mathrm{a}}$ \\
\hline
\end{tabular}

Each value is the mean \pm standard error of three replicates. Mean followed by the same alphabet are not significantly $(P>0.05)$ different from each other using Duncan's new multiple range test ${ }^{-}$ 
Fumigant toxicity of synergistic application of leaf and root bark powder of $P$. alliacea on the mortality of adult Culex quinquefasciatus

The synergistic effect of leaf and root bark of $P$. alliacea on the mortality of adult Culex quinquefasciatus is presented in Table 3. At all grams of powder concentration, no adult mortality was recorded at $30 \mathrm{~min}$ posttreatment periods except from $5 \mathrm{~g}$ that caused adult mortality of $5.00 \%$ and was significantly $(P<0.05)$ different from all others. At $1 \mathrm{~h}$ post-treatment periods, $1-2 \mathrm{~g}$ powder concentration caused $8.33-11.67 \%$ adult mortality and were not significantly $(P>0.05)$ different from each other while at 3-4 g powder concentration 30.00$31.67 \%$ adult mortality was recorded but were not significantly $(P>0.05)$ different from each other. At $5 \mathrm{~g}$ powder concentration, $46.67 \%$ adult mortality was recorded which was significantly $(P<0.05)$ different from all others. At $1 \mathrm{~h} 30 \mathrm{~min}$ post-treatment periods, 1-5 g powder concentration caused $18.33-63.33 \%$ adult mortality were all significantly $(P<0.05)$ different from each other as well as the control. At $2 \mathrm{~h}$ post-treatment periods, $1-5 \mathrm{~g}$ powder concentration caused $25.00-75.00 \%$ adult mortality which were all significantly $(P<0.05)$ different from one another as well as the control.

\section{Lethal dosage effect of Petiveria alliacea powder after $2 \mathrm{~h}$} post-treatment period

Table 4 shows the lethal dosage of powder that kills 50\% and $90 \%$ of the adult Culex quinquefasciatus after $2 \mathrm{~h}$ post-treatment interval. $\left(\mathrm{LD}_{50}(\mathrm{LCL}-\mathrm{UCL})\right)$ values are 3.76 (3.156-4.782), 2.86 (2.460-3.356), and 2.63 (2.2683.046) g, respectively; $\left(\mathrm{LD}_{90}(\mathrm{LCL}-\mathrm{UCL})\right)$ values are recorded as 25.6 (14.506-69.838), 15.25 (10.277-28.876), and 12.94 (9.124-23.053) g, respectively.

\section{Discussion}

Culex pipiens and Culex quinquefasciatus are the two Culex species with the most important public health

Table 3 Fumigant toxicity of synergistic application of Petiveria alliacea leaf and root bark powder on the mortality of adult Culex quinquefasciatus

\begin{tabular}{lllll}
\hline $\begin{array}{l}\text { Weight } \\
\text { (g) }\end{array}$ & \multicolumn{4}{l}{ \%Mortality after } \\
\cline { 2 - 5 } & $\mathbf{3 0} \mathbf{~} \mathbf{m i n}$ & $\mathbf{1 ~ h}$ & $\mathbf{1} \mathbf{h ~} \mathbf{3 0} \mathbf{~} \mathbf{~ i n}$ & $\mathbf{2 ~ h}$ \\
\hline 1 & $0.00 \pm 0.00^{\mathrm{a}}$ & $8.33 \pm 0.33^{\mathrm{b}}$ & $18.33 \pm 0.33^{\mathrm{b}}$ & $25.00 \pm 0.00^{\mathrm{b}}$ \\
2 & $0.00 \pm 0.00^{\mathrm{a}}$ & $11.67 \pm 0.33^{\mathrm{b}}$ & $28.33 \pm 0.33^{\mathrm{c}}$ & $36.67 \pm 0.33^{\mathrm{c}}$ \\
3 & $0.00 \pm 0.00^{\mathrm{a}}$ & $30.00 \pm 0.00^{\mathrm{c}}$ & $40.00 \pm 0.00^{\mathrm{d}}$ & $53.30 \pm 0.33^{\mathrm{d}}$ \\
4 & $0.00 \pm 0.00^{\mathrm{a}}$ & $31.67 \pm 0.33^{\mathrm{c}}$ & $51.67 \pm 0.33^{\mathrm{e}}$ & $60.00 \pm 0.00^{\mathrm{e}}$ \\
5 & $5.00 \pm 0.00^{\mathrm{b}}$ & $46.67 \pm 0.00^{\mathrm{d}}$ & $63.33 \pm 0.33^{\mathrm{f}}$ & $75.00 \pm 0.00^{\mathrm{f}}$ \\
Control & $0.00 \pm 0.00^{\mathrm{a}}$ & $0.00 \pm 0.00^{\mathrm{a}}$ & $0.00 \pm 0.00^{\mathrm{a}}$ & $0.00 \pm 0.00^{\mathrm{a}}$ \\
\hline
\end{tabular}

Each value is the mean \pm standard error of three replicates. Mean followed by the same alphabet are not significantly $(P>0.05)$ different from each other using Duncan's new multiple range test importance. The approach to combat these diseases largely relied on the disease transmission cycle by either targeting the mosquito larvae through spraying their breeding sites or by killing the adult mosquito using insecticides (Ogunleye \& Ibioteye, 2003). Nevertheless, due to the challenges of high cost and development of resistance in many vector mosquito species to several synthetic insecticides, interest has been made in exploring the pest control potential of botanicals (Luz et al., 2016). Also, economic and environmental concerns have encouraged a tendency recently toward the use of soft pesticides (Awad, 2003).

The result of this current research revealed that the powder of $P$. alliacea was slightly effective against adult Culex quinquefasciatus. This might be due to the main active ingredients been captured within the powder unlike the oil extract in which the active ingredient has been dissociated by ethanol. The effect could also be attributed to the chemical constituents of the plant powder which might have caused neurological disorder in the adult mosquito. The leaf powder has no effect during the first 30 min of post-exposure time and no mortality was recorded. However, at longer exposure period of $2 \mathrm{~h}$ $60.00 \%$, mortality was recorded which was very similar to the work of Akinneye, Obimakinde, Osunyemi, Owoeye, and Chime (2019), where the powder of Zingiber officinale caused mortality of $90.00 \%$ after $1 \mathrm{~h} 30$ min while no mortality was recorded in the first $30 \mathrm{~min}$ of exposure period for all concentration. However, $Z$. officinale shows more potency when compared to the present study. Akinneye and Afolabi (2014) reported the fumigant effect of powder of Cleisthopholis patens against adult Anopheles mosquito, the findings reveals that $P$. alliacea was more effective compared to $C$. patens with a mortality of $48.33 \%$ and $36.70 \%$, respectively, at the highest concentration after an exposure period of $1 \mathrm{~h} 30 \mathrm{~min}$.

The root powder indicated more effectiveness compared to the leaf possibly due to the presence of more insecticidal properties in the root bark. The result evaluated from this study revealed no mortality was recorded for the first $30 \mathrm{~min}$ for all concentrations apart from $5 \mathrm{~g}$ which shows $5 \%$ mortality. After $2 \mathrm{~h}$ of exposure time, the root powder was slightly effective against adult Culex mosquito causing mortality of $71.60 \%$ at all concentrations. The synergistic effect of the root and leaf powder of the plant shows more effectiveness compared to other powders that were used, showing mortality of 25.00$75.00 \%$ at different concentration after $2 \mathrm{~h}$ of exposure period. Generally, the powders derived from this plant are less effective, possibly due to the active components not been readily available for action unlike the oil extract that the active chemicals are extracted and available for action. However, at higher concentration of powder, the 
Table 4 Lethal dosage effect of Petiveria alliacea powder after $2 \mathrm{~h}$ post-treatment period

\begin{tabular}{|c|c|c|c|c|c|c|c|c|}
\hline \multirow{2}{*}{$\begin{array}{l}\text { Plant } \\
\text { powder }\end{array}$} & \multirow{2}{*}{$\begin{array}{l}L_{50} \\
\text { (g) }\end{array}$} & \multicolumn{2}{|c|}{ 95\% Confidence limit } & \multirow{2}{*}{$\begin{array}{l}\mathrm{LD}_{90} \\
(\mathrm{~g})\end{array}$} & \multicolumn{2}{|c|}{ 95\% Confidence limit } & \multirow[t]{2}{*}{ Slope } & \multirow[t]{2}{*}{$x^{2}$} \\
\hline & & $\overline{\mathrm{LCL}}$ & UCL & & $\overline{\mathrm{LCL}}$ & $\mathrm{UCL}$ & & \\
\hline Leaf & 3.76 & 3.156 & 4.782 & 25.06 & 14.506 & 69.838 & 1.555 & 0.701 \\
\hline Root & 2.86 & 2.460 & 3.356 & 15.25 & 10.277 & 28.876 & 1.763 & 2.313 \\
\hline Root and leaf & 2.63 & 2.268 & 3.046 & 12.94 & 9.124 & 23.053 & 1.851 & 3.262 \\
\hline
\end{tabular}

$L D 50$ lethal dosage that kills $50 \%$ of the exposed adult, $L D_{90}$ lethal dosage that kills $90 \%$ of the exposed adult, $L C L$ lower confidence limit, $U C L$ upper confidence limit, slope, $X^{2}$ chi-square

efficacy will be more lethal in relative to the time exposure. The lethal concentration $\left(\mathrm{LD}_{50}\right)$ of the leaf, root, and synergistic effect of leaf and root powder required to kill $50 \%$ of the Adult Culex quinquefasciatus was 3.76 g, $2.86 \mathrm{~g}$, and $2.63 \mathrm{~g}$, respectively. However, $25.06 \mathrm{~g}$, $15.25 \mathrm{~g}$, and $12.94 \mathrm{~g}$ of the leaf, root, and leaf and root were required to kill $90 \%\left(\mathrm{LD}_{90}\right)$ after $2 \mathrm{~h}$ of exposure period.

Several other works have carried out on this plant for their medicinal use of this plant. Sathiyabalan, Paulpriya, Muthukumarasamy, and Mohan (2017), in his study, investigated the Pharmacognostic parameters that include macroscopic, microscope, physiochemical attributes, fluorescence analysis, and phytochemical screening, and the salient diagnostic features were also documented. The preliminary physiochemical screening of methanol and ethanol extracts of his study on Petiveria alliacea whole plant revealed the presence of alkaloids, coumarins, flavonoids, saponins, steroids, phenols, tannins, Terpenoids, glycosides, and xanthoproteins. However, previous works on $P$. alliacea revealed the presence of triterpenoids, saponins, polyphenols, benzaldehyde, benzoic acid, flavonoids, fridelinol, pinitol, and allantonin. The study of Ogunneye, Osinubi, Ogundiran, Adewoga Thomas, and Gbadebo (2016) also reveals similar phytochemical components. This plant has also been reported to be a potential antitumor (Queitilane de et al., 2016). These compounds are readily present in the plant. However, they might be responsible for the mortality of the adult Culex quinquefasciatus.

\section{Conclusion}

Due to the toxic action against adult Culex quinquefasciatus, $P$. alliacea leaf and root bark powder shows potentiality to suppress the population of Culex quinquefasciatus. The powder of $P$. alliacea is promising for the use in the control of filariasis vector. The present findings have important implications in the practical control of adult mosquito by using botanical insecticides. These plant powders are easy to prepare, inexpensive, and safe for mosquito control which possesses enough insecticidal potential and can be used directly around human dwellings. The result suggests possible utilization of the cheap and readily available botanicals for possible control of mosquitoes as part of an integrated vector management program. However, large-scale harvesting from nature will not be sustainable in the long run and hence cultivation in marginal areas could be considered an option. Previous works on the phytochemical screening of the leaf and root bark of $P$. alliacea showed the presence of alkaloids, flavonoids, saponins, steroids, phenols, tannins, terpenoids, glycosides, and reducing sugar. The presence of these phytochemicals in the leaf and root of $P$. alliacea confer them for their insecticidal values.

\section{Abbreviations}

$\mathrm{LD}_{50}$ : Lethal dosage required to kill $50 \%$ of the insect population; $\mathrm{LD}_{90}$ : Lethal dosage required to kill $90 \%$ of the insect population

\section{Acknowledgements}

I acknowledge the effort of Dr. J. O. Akinneye (Supervisor), Mr. Olabimi Isaac, llelakinwa Oluwatosin, and every other person that helped in the success of this research.

\section{Authors' contributions}

J.O.A designed the experiment and also helped in determining the concentration used for the work and A. M. O. carried out the laboratory works, statistical analysis of the research while O. B. I interpreted the results. All authors read and approved the final manuscript.

\section{Funding}

The research work was self-funded.

\section{Availability of data and materials}

All data were gotten from the laboratory after several experiments have been conducted. The raw data are readily available if needed. No data were gotten from journals or past research works.

Ethics approval and consent to participate

Not applicable.

\section{Consent for publication}

Not applicable.

\section{Competing interests}

The author(s) declare(s) that there is no conflict of interest regarding the publication of this paper.

\section{Author details}

${ }^{1}$ Department of Biology (Environmental Biology and Public Health Unit), Federal University of Technology, PMB 704, Akure, Ondo-State, Nigeria.

${ }^{2}$ Department of Biology (Entomology Unit), Federal University of Technology, PMB 704, Akure, Ondo-State, Nigeria.

Received: 20 August 2020 Accepted: 15 December 2020

Published online: 07 January 2021

\section{References}

Abbott, W. S. (1925). A method of computing the effectiveness of an insecticide. Journal of Economic Entomology, 18, 265-267. 
Ajayi, I. A., \& Ojelere, O. O. (2010). Chemical composition of ten medicinal plant seeds from Southwest Nigeria. Advances in Life Science and Technology., 10, 25-32.

Akinneye, J. O., \& Afolabi, O. J. (2014). Toxicity and fumigant effect of powder and oil extract of Cleithopholis patens (Benth) against larvae and adult Anopheles mosquito. Journal of Mosquito Research., 4(11), 1-6.

Akinneye, J. O., Obimakinde, E. T., Osunyemi, O. S., Owoeye, A. J., \& Chime, P. T. (2019). Management of Anopheles mosquito larvae and adult with Zingiber officinale powder and oil extract. International Journal of Pure and Applied Zoology., 7(1), 1-6.

Alegre, J. C., \& Clavo, M. (2007). Petiveria alliacea L. (Internet) Record from PROTA4U. In G. H. Schmelzer, \& A. Gurib-Fakim (Eds.), PROTA (Plant Resources of Tropical Africa/Ressources végétales de l'Afrique tropicale), Wageningen, Netherlands.

Awad, O. M. (2003). Operational use of neem oil as an alternative anopheline larvicide. Part B: environmental impact and toxicological potential. Eastern Mediterranean Health Journal, 9(4), 646-658.

Awolola, T. A., Oduola, I. O., Oyewole, J. B., Obansa, C., Amajoh, L., \& Koekemoer, L. L. (2007). Dynamics of knockdown pyrethroid insecticide resistance alleles in a field population of Anopheles gambiae. in southwestern Nigeria. Journal of Vector Borne Diseases, 44, 181-188.

Barroso, G. (2004) Sistematica de angiospermas do Brasil. Livros Técnicos e Científicos Editora 1. Joly A (2004) Botanica 12 (eds). Sao Paulo7 Nacional.

Bekele, D., Petros, B., Tekie, H., \& Asfaw, Z. (2014). Larvicidal and adulticidal effects of extracts from some indigenous plants against the malaria vector, anopheles arabiensis (Diptera: Culicidae) in Ethiopia. Journal of Biofertilizer and Biopesticide., 5, 144.

Cronquist, A. (2002). The evolution and classification of flowering plants. Bronx: New York Botanical Garden.

De Andrade, T. M., de Melo, A. S., Dias, R. G., Varela, E. L., de Oliveira, F. R., et al. (2012). Potential behavioural and pro-oxidant effects of Petiveria alliacea $L$. extract in adult rats. Journal of Ethnopharmacology., 143, 604-610.

Ghosh, A., Mukherjee, S., Dutta, T., Roy, S., \& Mondal, F. B. (2013). Community perceptions regarding mosquito borne diseases in some selected localities of Bankura, a peri-urban area of West Bengal. India Journal of Mosquito Research. ,3(7), 54-57.

Luz, D. A., Pinheiro, A. M., Silva, M. L., Monteiro, M. C., \& Prediger, R. D. (2016). Ethnobotany, phytochemistry and neuropharmacological effects of Petiveria alliacea L. (Phytolaccaceae): A review. Journal of Ethnopharmacology, 185, 182-201.

Oduola, A. O., Obansa, J. B., Ashiegbu, C. O., Otubanjo, O. A., \& Awolola, T. S. (2010). High level of DDT resistance in the malaria mosquito: Anopheles gambiae from rural, semi urban and urban communities in Nigeria. International Journal of Environmental Research and Public Health., 9, 114-120. 24.

Ogunleye, D., \& Ibioteye, S. F. (2003). Studies of antimicrobial activity and chemical constituents of Ximenia Americana. Tropical Journal of Pharmaceutical Resources, 2, 239-241.

Ogunneye, A. L., Osinubi, A. D., Ogundiran, A. A., Adewoga Thomas, O. S., \& Gbadebo, O. R. (2016). Qualitative and quantitative evaluation of phytochemical constitution of leaf and root of Petiveria alliacea using spectrophotometric technique. In Interdisciplinary conference of Tai Solarin University of Education.

Queitilane de, S. S., Fernanda, M. B., Amaro, C. R., Marina, M. P., Maria, R. G. V., Milton, M. K., \& Rodrigo, R. O. (2016). Phytochemical analysis and cytotoxic activity of Petiveria alliace (Phytolaccaceae). International Journal of Science., 5 , 53-58.

Sathiyabalan, G., Paulpriya, K., Muthukumarasamy, S., \& Mohan, V. R. (2017). Pharmacognostical, physicochemical and phytochemical standardization of Petiveria alliacea L. International Journal of Pharmacognosy and Phytochemical Research., 9(2), 233-241.

Schmelzer, G., \& Gurib-Fakim, A. (2008). Medicinal plants. Plant resources of tropical Africa, (pp. 412-415).

World Health Organization (1996). Report of WHO informal consultation on the evaluation and testing insecticides, CTDMHO PES/IC/96.1, (p. 69)

Yerpude, P. N., Jogdand, K. S., \& Jogdand, M. (2013). A study on awareness and practice about preventive methods against mosquito bite among households in an urban slum area of South India. International Journal o Recent Trends in Science and Technology, 8(2), 69-71.

\section{Publisher's Note}

Springer Nature remains neutral with regard to jurisdictional claims in published maps and institutional affiliations.

\section{Submit your manuscript to a SpringerOpen ${ }^{\circ}$ journal and benefit from:}

- Convenient online submission

- Rigorous peer review

- Open access: articles freely available online

- High visibility within the field

- Retaining the copyright to your article

Submit your next manuscript at $\boldsymbol{\nabla}$ springeropen.com 